REVISTA CHILENA DE LITERATURA

Noviembre 2009, Número 75, 233 - 258

\title{
EL CULTO A LO FEO Y EL INVUNCHISMO EN CHILE SEGÚN JOAQUÍN EDWARDS BELLO ${ }^{1}$
}

\author{
Catalina Uribe Echeverría \\ Universidad de Chile \\ curibeecheverria@yahoo.es
}

RESUMEN / ABSTRACT

Este trabajo pretende abordar el culto a lo feo o invuchismo, una observación o definición llena de ironía que acuñó por primera vez Joaquín Edwards Bello en los años 20 y que muestra la tendencia de deformación hacia lo monstruoso o repulsivo en lo chileno. Para el cronista y escritor, Chile - o finis mundi- es un país con una apariencia de mesura en un trasfondo de crueldad, brutalidad y excesos. De la naturaleza extrema surge un hombre desgarrado, aún bajo el peso de la noche (una suerte de metáfora del inconsciente colectivo), con una gran fuerza de resistencia y absorción. ¿Siguen siendo los chilenos iguales de brutales y desgarrados que sus antepasados? ¿Cómo puede explicarse esta nefasta tendencia a destruir, demoler la naturaleza y las ciudades? ¿Dónde se manifiesta lo feo en la vida cotidiana del chileno? Estas son algunas de las interrogantes que se intentará abordar en este ensayo.

Palabras clave: Joaquín Edwards Bello, Chile, culto a lo feo, invunche (o imbunche), demolición, desgarro.

This work intends to examine the cult of ugliness or "invunchismo", an ironic concept first coined up in the 1920s by the writer Joaquin Edwards Bello, in reference to a Chilean exacerbation of deformation into monstrosity and repulsiveness. According to the author, Chile -or finis mundi- is a country whose apparent moderation masks a reality of cruelty, brutality, and excess. From an uncompromising natural background emerges a tormented creature, still

1 Este trabajo tuvo su origen y orientación temática en el curso de postgrado de literatura de la Universidad de Chile "Crítica a la vida cotidiana chilena, carta, crónica urbana, diario íntimo”, impartido por el profesor Leonidas Morales en el año 2008. 
burdened by the "weigh of the night" (a metaphor for the unconscious), yet capable of great resilience and assimilation. Are Chileans still as brutal and tormented as their ancestors? What can account for this harmful tendency towards destruction and devastation of the cities and the natural world? What are the manifestations of ugliness in the daily life of Chileans? These are some of the topics that this work will attempt to review.

KEY WORDS: Joaquín Edwards Bello, Chile, cult of ugliness, Invunche (o Imbunche), demolition, torment.

¿Qué encontramos al caminar desde la Plaza de Armas de Santiago de Chile, por Ahumada hasta la calle Huérfanos? En la plaza ya casi nada hay de lo que la caracterizaba, muchos árboles volaron y el cemento arrecia. Hoy, una mole de piedra que escasamente podría decirnos algo sobre el indígena quiere representarlo en una esquina. Se supone que es una escultura. Ya no están los y las jóvenes que se dedicaban a recorrer la plaza, mujeres hacia un lado, hombres hacia el otro, con la esperanza de encontrarse a través de la mirada con el amor de su vida. Infinidad de mendigos, indigencias solapadas, seres extraviados de sí mismos vegetan hoy sin sentido entre los bancos. Sordidez es lo que caracteriza ahora este lugar, centro histórico de la nación.

Algunos edificios aún no han sido víctimas hasta el mes de julio de 2008 del culto por la demolición que caracteriza a los chilenos. Aún están en pie la Catedral, el edificio actual de correos, los portales varios, indicios arquitectónicos que nos permiten suponer la existencia de algún pasado de decencia para este país. Pero entre la plaza y la calle Huérfanos resulta dificilísimo imaginarse las vitrinas de acuario con la exposición de bellezas del fotógrafo Heffer, que relata Joaquín Edwards Bello en alguna de sus crónicas. Para el escritor chileno ya en su época y desde fines del siglo XIX (excepcionalmente la crónica a la que aludimos, El Hotel Oddó, cuenta con una indicación respecto del año de redacción -1954- pues la mayoría de la crónicas editadas por Alfonso Calderón no cuentan ni con la fecha ni con el lugar de su publicación) la tendencia a la desaparición, a la destrucción, a la demolición, caracteriza a la idiosincrasia de nuestro país.

Este trabajo pretende abordar el culto a lo feo o invuchismo ${ }^{2}$, una observación o definición que acuñó por primera vez Joaquín Edwards Bello en los

2 La ortografía de la palabra invunche -o imbunche- fue objeto de reflexión para Joaquín Edwards Bello, abogando por la primera. En el presente trabajo optaremos por escribir 
años 20 y que fue analizada posteriormente por otro agudo observador de la realidad de nuestro continente, el filósofo alemán Hermann von Keyserling, muy citado por el mismo Edwards. Si ya a comienzos del siglo XX el escritor chileno registraba con horror y humor en sus crónicas esta tendencia nacional, ¿qué habría dicho Edwards Bello del Chile de hoy? Se habrá dado ya varias vueltas en su tumba, para recoger una brutal expresión "chilena". Hoy el absurdo, lo feo, el invunchismo, la demolición siguen imperando, reinando más bien.

Unos días apenas antes de la redacción de este trabajo se dio la noticia en los diarios nacionales acerca de un túnel construido con las últimas tecnologías y avances que exigen las obras viales del siglo XXI. El túnel que atraviesa el cerro de San Cristóbal fue elaborado por una empresa privada gracias al famoso sistema de concesiones del Ministerio de Obras Públicas y se inauguró a comienzos de julio de 2008; pero posee una característica que me atrevería a calificar de muy chilena. Es un túnel que no lleva a ninguna parte. El 'pequeño' inconveniente de la obra avalada por todas las autoridades de gobierno, e inaugurada por el mismísimo ministro de la cartera, es que, pese a poseer cuatro modernas pistas en su interior para cumplir con su objetivo de facilitar el tránsito de vehículos, su salida resulta prácticamente inutilizable. Tal como diría Edwards Bello, refiriéndose en 1961 al túnel de Lo Prado, la construcción "empezó mal" -por las múltiples manifestaciones de rechazo de vecinos de Pedro de Valdivia Norte, en el caso actual-y "terminó mal" (Edwards Bello, Hotel Oddó, "Despedida de la Sombrerería Presciutti” 23), por el absurdo inconveniente a que hacíamos alusión. Una vez más, la planificación no existió o falló, el Estado comete el aberrante hecho de tener que pagar millonarias multas a la empresa concesionaria por el atraso de las construcciones a la salida del citado túnel. No corresponde aquí entrar en el detalle de los sinsentidos de las políticas públicas del actual gobierno chileno.

Este pequeño resumen de una noticia reciente tiene tan solo el propósito de mostrar que la lectura de las más de diez mil crónicas que el escritor y periodista Joaquín Edwards Bello escribiera entre los años 20 y fines de los 60 resulta asombrosamente contemporánea y exacta. Una agudeza dramática

invunche, no obstante reproduciremos la palabra tal como aparece en las crónicas, ignorándose si la elección fue el objeto o no de alguna errata de la publicación original. 
para cualquier habitante y testigo de la cotidianeidad del Santiago de hoy. Por ello es un ejercicio casi intrigante descubrir directamente en las citas de Edwards Bello, que reproduciremos de adrede de manera extensa en este trabajo, cómo este escritor nacido a fines del siglo XIX expresa de manera tan exacta e irónica realidades, defectos y escasas virtudes que padecemos aún hoy.

¿Siguen siendo los chilenos iguales de brutos y desgarrados que sus antepasados? ¿Cómo puede explicarse esta nefasta tendencia a destruir, demoler, los pocos lugares interesantes de la ciudad, de muchas ciudades y rincones del país? ¿Dónde se manifiesta lo feo, según Joaquín Edwards Bello, en la vida cotidiana del chileno? ¿Cuáles son algunas de las características preponderantes en el carácter del chileno que lo llevan a cultivar lo feo en su manera de relacionarse con su naturaleza, de enfocar la realidad y de construir una existencia social en la ciudad? Estas son algunas de las interrogantes que se intentará abordar en el presente trabajo.

\section{LA NATURAL BRUTALIDAD DE UN PAISAJE DE EXCESOS}

El último rincón del mundo, un acabamiento de tierra, finis mundi, numerosas son las maneras que se han utilizado para referirse a Chile y a su loca, o al menos peculiar, geografía. Un país de paisajes opuestos: de aridez profunda, de fríos glaciales, de bosques centenarios, pero con valles templados. Una apariencia de mesura en un trasfondo de brutalidad y excesos. Un país con una naturaleza extrema y de difícil acceso, una franja de tierra al borde de un acantilado, flanqueada por una imponente cadena cordillerana y por un espeluznante y abrupto -aunque invisible a ojo humano- hundimiento marino que hace que los chilenos vivamos en la práctica parados en el precario borde de un abismo. Como escribió Armando Uribe, "verdaderamente es probable que el destino de Chile sea correrse entero hacia el mar, resbalando a la insondable fosa geológica de la costa del Pacífico, y quedar sepultado ahí en la justicia de toneladas de agua yodada y salobre, caballeros y rotos, pobres y ricos, juntos pero no revueltos (amicitia sed non familiaritas, tampoco en la muerte)" (Uribe 117). Un país de durezas, géiseres y volcanes, que hace a sus habitantes sujetos de los fuegos profundos del centro de la tierra. El lugar de encuentro de dos placas tectónicas que hacen de su suelo un inseguro paraje, siempre expectante al movimiento telúrico. 
En palabras de Miguel Serrano, el chileno vive angustiado por su paisaje, un paisaje duro de una belleza inmaculada, cruel e inaccesible...
"el chileno que aquí vive, se impregna del horror de algo duro y tremendo, de algo que fatalmente sucederá. La tierra le da todo y, por lo general, le quita todo. Le quita lo que hace un momento le ha dado, o lo que con mucho sacrificio y esfuerzo, él había logrado construir. La tierra se mueve un poco, se sacude; el volcán vomita y todo se desmorona y se pierde. El hombre levanta entonces la cabeza y mira el cielo: ‘¿Volveré a comenzar otra vez?’. El hombre se hace fatalista. ‘¿Para qué?’ -piensa-. (...) Al paso del tiempo la estatura del hombre disminuye, se caen sus dientes, se enferman sus pulmones. Y ello a vista y presencia de la altiva belleza del paisaje, impasible y despiadado. Tierra soberbia, hombres moribundos. (...) El alma del chileno se llena de terrores y presagios. (...) ¡Tan angosta y raquítica es la faja que nos queda para transitar entre la cordillera y el mar! (...) Como aún en Chile no hemos aprendido a mirar arriba, solo podemos bajar la cabeza al suelo y mirar hacia abajo, o, cuando mucho, hacia adentro" (Serrano 96-97).

Pero, desgraciadamente este chileno incapaz de mirar el cielo, según Serrano, es un hombre poco dado a mirar hacia adentro, poco dado a apreciar lo que se le dio. Entre 1922 y 1924, en alguna de sus crónicas publicadas en el diario La Nación, Joaquín Edwards Bello fue el primero en referirse al "cultivo de la fealdad" como una de las características más marcadas de nuestra idiosincrasia: "me precio de haber sido el precursor chileno en anotar un hecho nacional: el cultivo del fracaso y de la fealdad. La tendencia al fenómeno del imbunche: creación araucana de monstruosidad alucinante. Se trata de la forma saliente de demostrar un estado crónico de desolación, de crueldad y de odio" (Edwards Bello, Nuevas Crónicas, "Filosofía rusticana" 47).

Muchos de los paisajes chilenos muestran dicha desolación, no solo el nortino desierto con su aridez a toda prueba, los bosques del sur poseen una majestuosidad y abundancia también de difícil supervivencia, y más hacia el fin del continente, la pampa, las nieves y los canales fueguinos, que se describen por ejemplo en Jemmy Button de Benjamín Subercaseaux, son asombrosamente crudos y hostiles para la subsistencia.

Citando al escritor brasileño Assis Chateaubriand, Edwards Bello observa: "El chileno aprende a vivir peligrosa y cautelosamente en su abismo. El destino es duro con el chileno (...). Chile, este nombre por sí mismo, es equivalente de inseguridad y de incertidumbre. Último rincón del mundo. 
Acabamiento de tierras. Finis Mundi" (Edwards Bello, Crónicas, "La tragedia chilena" 73).

La naturaleza de Chile no fue bien preciada por sus hombres, al menos por aquellos que la poblaron luego de la llegada de los españoles. Es la miseria de Chile, que conlleva sus características de desidia, mala voluntad e impulsos agresivos, según observa Luis Oyarzún, al encontrar araucarias inútilmente abatidas en Panguipulli:

"El chileno proyecta su feísmo de población callampa a la naturaleza y por eso no le cuesta arruinar su hermosura. Él no mira el paisaje ni tiene la capacidad de verlo en perspectiva, que exige una condición mental superior, la facultad de desprendimiento estético y moral. Los montes, las selvas, las cascadas impresionan al chileno por su magnitud, como expresión espectacular de fuerza, y no por su belleza, tal como podrían deslumbrarlo un portaviones o un terremoto" (Oyarzún, Diario íntimo 328).

Quiénes son y qué hicieron los chilenos de su naturaleza. Pocos hombres en tierras vastas, de soledad y desgarro, una mezcla de guerreros que mandaban en su territorio con aguerridos y ambiciosos hombres en busca de oro y gloria. Según consigna Edwards Bello, "en la obra Arenas del Mapocho, por Ricardo Puelma R., este autor hace la siguiente confesión; "Yo nací muy soberbio: me gusta torturar a los demás y también torturarme". Miles podríamos firmar sin hipocresía la confesión de Puelma. Hacen mal en mirarnos a los chilenos como personas de este mundo, puesto que somos el fin del mundo. Acabamiento de tierras. Terremoto" (Edwards Bello, Hotel Oddó, "Crueldad en la literatura latinoamericana, 1954" 84).

Cuando el suelo agrede, el hombre se vuelve feroz e irrespetuoso. El paisaje donde concluye la tierra es a juicio de nuestro cronista de una violencia y tan marcados vértices que no se encuentra nada semejante en otras partes del planeta.

"Chile, tierra de temblores, llegó tarde el día del reparto del buen gusto y de la medida. No conoce términos medios. La naturaleza hace al hombre tosco y feo. El hombre ayuda a la naturaleza y se venga declarando la fuerza y belleza de la fealdad. Los poetas son desesperados, de terremoto y de alcohol. (...) Poesía de desintegración, de dolor, de penitencia, de violencia, de desesperanza, de andrajo. Algo que se ha roto. Símbolo de Chile: roto" (Edwards Bello, Hotel Oddó, "Crueldad en la literatura latinoamericana, 1954" 81). 
Este personaje, el roto, símbolo del alma nacional, se caracteriza por sus andrajos, su violencia, su capacidad de supervivencia ante lo hostil.

Hablando de su Valparaíso natal, Edwards escribe:

"Esos cerros están separados, partidos por profundos barrancos y quebraduras; de todas partes se ve el mar como en un vértigo. Los colores, las piedras, la vegetación, la tierra, todo es violento, insinúa la idea del cataclismo volcánico. ¿Qué panorama del mundo es parecido a ese? Yo no he visto hasta ahora nada que me lo recuerde en los viajes (...) Valparaíso tiene angulosidades y extravíos de dibujo cubista. (...) Arriba de cualquier cerro donde uno sube por placer el viento es más recio, barre el suelo, silba como culebra y echa una granizada de arenilla imperceptible que se mete por los ojos y que en la noche encontramos en los zapatos" (Edwards Bello, Crónicas, "Tierra de temblores" 95).

Respecto del desierto chileno, Edwards Bello dice: “en general, toda esa tierra es como un cadáver de tierra, como una momia. El paisaje, silencioso, ensimismado, anestesiado, es un paisaje que ha mascado la coca. Todo convida a la meditación y la tristeza. La gente piensa lentamente, ingenuamente, y hasta las historias banales (...) tienen una ilusión, un hechizo de espejismos en la memoria" (Edwards Bello, Nacionalismo continental, "La salitrera" 89-90).

Esta descripción se refiere al habitante del norte de Chile, el indio de la zona altiplánica, que se acerca más al indio quechua o aymara que al mapuche. Edwards destaca como una característica del indio americano la medida de su pulso, diez pulsaciones menos que en la raza blanca, un factor a partir del cual "deducen cierta forma de insensibilidad o indiferencia". Este concepto se asemeja al de la gana que ideó el filósofo Keyserling en sus Meditaciones Suramericanas y que se le hizo patente un día que jugaba al tenis en las afueras de Córdoba, Argentina. Le ofreció a un chiquillo un peso por hora si se encargaba de recoger las pelotas. "El chiquillo meneó melancólicamente la cabeza:-“No puedo”. -“¿Por qué?” -"Porque no tengo gana"” (Keyserling 165). Esta gana continental es un impulso ciego, la más fuerte de las fuerzas y la más débil de las debilidades, poder elemental e impotencia al mismo tiempo, algo innominado e innominable. Es pasión pero también pasividad. Puede parecer pereza pero Keyserling señala que los sudamericanos son capaces de llevar a 
cabo los trabajos más prodigiosos. El americano padece su vida. Su vida es una capitulación continua ante el impulso interior. La melodía de la gana es monótona pero interrumpida por explosiones súbitas y violentas de energía represada: revoluciones, entusiasmos, terremotos. Y como son ciegas, estas explosiones jamás consiguen progreso alguno. La gana americana es melancolía y escepticismo sin fondo. "Jamás sucede nada nuevo. Nada sirve de nada. En nada puede confiarse. Ningún esfuerzo vale la pena" (Keyserling 184). Su sino es la fatalidad.

Tenemos entonces una naturaleza violenta que engendra un hombre violento. Pero tal como la naturaleza es aparentemente benigna y anodina, el hombre también parece estar a la espera eternamente de algún acontecimiento, o quizás de ninguno. En relación al clima, Edwards Bello sostiene, "es muy sabido que el clima sudamericano oscurece la piel del europeo. Hace aparecer una pantalla plomiza en las caras, a manera de máscara defensiva. Color indio. Nuestro clima modifica no solamente el color de la piel, sino la contextura de los cabellos, de los ojos, de todo el cuerpo, del carácter. Hay un decrecimiento de los miembros y ensanchamiento del tórax. Cambian las pulsaciones y el aparato respiratorio" (Edwards Bello, Nuevas Crónicas, "Cremas para el cutis" 12). El pulso es más lento, la sangre parece ser más fría. Según Keyserling, es este el continente del tercer día de la creación, con un paisaje áspero y desolado en su puna altiplánica y seres serpentinos.

Del paisaje, Edwards Bello pasa al hombre, las características del uno se permean en el otro, para bien o para mal. Ciertas concepciones raciales son típicas del comienzo del siglo XX. Luego de la II Guerra Mundial adquieren otras connotaciones. Proporciones corporales, predominancia de colores suelen asimilarse a los rasgos espirituales de los seres. No obstante, muchas observaciones de Edwards Bello conservan una agudeza llena de ironía, a veces despiadada con todos, los otros y los cercanos. Nuestro autor desertó de hecho de su propia clase y privilegios. Su descarnada visión en El inútil le valió el vacío de una casta que no perdona. E. Bello decía estar orgulloso de haber hecho el camino inverso de muchos caballeros que migraban del centro hacia los barrios altos.

Si tierra y hombre son indisociables, el subsuelo y su magnetismo también influyen en el ser chileno. Con un agudo humor ante horrorosas noticias de asesinatos, Edwards Bello teoriza respecto de las telúricas influencias en los estados espirituales y anímicos del hombre de Chile: 
"En Santiago hemos conocido una racha de asesinatos surtidos. Según las estadísticas, ningún país nos gana en las carreras de la muerte ¿Cuál es la causa del sangriento record? La tierra es una estrella que se enfría. Chile es una parte en que el fuego no se ha extinguido. Larga cadena de volcanes activos o apagados. Respiramos imperceptible polvo volcánico. A veces el suelo se cubre de polvo volcánico. Ocurrió así no hace mucho. Hay terremoto y maremoto. Esto es, movimientos súbitos anormales de la tierra y del mar. ¿No habrá, acaso, movimientos súbitos de espíritus o animamotus? Pido privilegio para el neologismo. No hay razas, sino climas. El hombre es un producto del clima. He notado en mi tierra que el hombre más calmoso y frío suele ser víctima de instantáneos desvaríos, pérdidas del freno, de self control, o de voluntad de salvación personal. (...) Causas: clima volcánico, terremotos y maremotos, poca leche, comidas con grasa y ají, alcohol, caída constante del peso, ausencia de imaginación y caries dentales. No se asombren. Cuando hay caries dentales hay caries espirituales" (Edwards Bello, Nuevas Crónicas, "Últimos crímenes celebrados en Santiago" 37).

Esta metáfora de la carie espiritual resume de manera tragicómica la furia profunda y difícil de desentrañar que padecen los chilenos, esa violencia soterrada. Hay un dolor enraizado que persiste como un fuego ancestral y que no se quita con nada. La paz es aparente, la pasividad es una máscara. En la crónica El sobregiro, Edwards compara los valles llenos de tranquilidad y clemencia con las escasas personas equilibradas de nuestro país: "Hay en nuestra tierra profundos desequilibrios y diferencias de terrenos, de climas, de niveles. La cordillera, el mar y los desiertos permiten la existencia de pequeños valles fértiles que asombran por su voluntad de ser" (Edwards Be1lo, Francisco Miranda y otros personajes, "El sobregiro" 180). Estas zonas corresponden para E. Bello a las pequeñas partes equilibradas y sensatas de nuestra nación, la de las honradas mujeres de obreros, la de las víctimas del sobregiro, un mal nacional de antiguo origen y de asombrosa actualidad en el Chile del neoliberalismo de mercado desregulado.

Tenemos un hombre que ha evolucionado genética y culturalmente en relación a su entorno pero que es de una extraña tozudez a la hora de protegerse de sus inclemencias. Tozudez relativa, que tiene mucho del interés o desinterés económico y político de las clases dominantes por mejorar, o tomar siquiera en consideración, el destino y el pasar de la mayoría del pueblo chileno: "cuando se habla del clima de Chile es un deber señalar la región de que se trata. En Santiago y de Santiago al sur el invierno es inclemente, 
en primer lugar, porque las casas no tienen calefacción. Las antiguas casas hasta 1920 parecían construidas para recibir chiflones helados a manera de frigidaires. Cierta dama inglesa en 1910 dijo que en un hotel chileno había visto por primera vez a hombres comiendo con sobretodo puesto y guantes" (Joaquín Edwards Bello, Hotel Oddó, "Del obispo Villaroel al mariscal Montgomery" 66-67).

El hombre americano, y especialmente el chileno, está acostumbrado a las tragedias, es pasivo ante las catástrofes naturales: "cada año ocurren inundaciones con caídas de casas y muertes de personas. No hay para qué asombrarnos. En 1953 dijeron, como antes en 1887 y en 1903, que era un año terrible" (Edwards Bello, Nuevas Crónicas, "Lluvias de ayer" 102). Las catástrofes son el pan de cada año. Quizás se transforman incluso en las únicas ocasiones en las que el chileno se vuelve solidario y participa de un alma nacional. Las tragedias, las reales o las inventadas por los poderes, los medios o intereses particulares, despiertan el espíritu caritativo, vuelcan a la nación hacia sí misma en un impulso de cercanía y comunión. Y a veces estos dramas no se deben a manifestaciones excepcionales de la naturaleza. Una simple lluvia que en cualquier otro paraje pasa desapercibida, en Chile se convierte al poco rato en un desborde inexplicable, un torrente digno del diluvio. ¿Acaso no es la misma lluvia que tradicionalmente se manifiesta año tras año? A fines del siglo XIX, las inundaciones en época de lluvia arrastraban "el mobiliario de los ranchos e incluso la vivienda misma, y también a la gente, si la sorprendía durmiendo; en esos casos aparecían en el río los cadáveres de los ahogados, especialmente de los niños" (Romero, Luis Alberto 169). Los inundados eran recogidos en hospedería, los albergues de entonces, pero se convertían en prisioneros de esta caridad si es que brotaba alguna epidemia, se convertían en propagadores que había que contener. Este horroroso panorama no dista demasiado del que se produce en el siglo XXI. Ya no fluyen los cadáveres por el río, pero la ciudad colapsa a las primeras lluvias y las precarias viviendas de los más pobres resisten apenas. La siguiente descripción de Edwards Bello es totalmente válida en la actualidad: "Si llueve una semana de seguido, cosa común, los cauces revientan, los esteros desbordan y toda la ciudad estalla, se rompe, se inunda, las casas se anegan, y algunas calles, como las he visto de niño, se hacen navegables con el agua corriendo de vereda a vereda" (Edwards Bello, Crónicas, "Tierra de temblores" 95).

¿Qué desidia, qué indiferencia o qué ineptitud persiste en los que tienen la capacidad de tomar decisiones para que pasen décadas y siglos, y se repitan 
los mismo fenómenos en los que los más desamparados terminan siempre sufriendo?

\section{EL APARENTE ORDEN DE UN PAÍS DESGARRADO}

Es este un país de apariencias. Apariencias de orden tradicional que han sido profusamente analizadas por los historiadores: "Desde la Conquista hasta nuestros días, hemos estado marcados por un orden fundado en la frustración: Chile no era ni tan rico como se suponía, ni tan hospitalario como daba a pensar el paisaje, cálido y pintoresco. Durante largo tiempo no fuimos otra cosa que una frontera de guerra en un rincón apartado del mundo" (JocelynHolt 190).

Como sostuviera el historiador Mario Góngora, Chile fue desde sus inicios una tierra de guerra y "son las guerras defensivas u ofensivas las que han constituido el motor principal" de la nacionalidad chilena (Góngora 72). Alfredo Jocelyn-Holt continúa explicando que en cualquier momento durante la Conquista castigaban el malón, el saqueo, el fuego, y había que volver a levantar todo. Una imagen que nos resulta habitual a los chilenos actuales. Sea por los embates de la naturaleza, sea por los embates de la codicia y crueldad humanas -política, social o económica-, en Chile sigue imperando la sensación de que en cualquier momento todo se derrumba. Tal como lo escribiera Miguel Serrano en la cita anteriormente expuesta, el chileno entonces se pregunta “'¿Volveré a comenzar otra vez?’. El hombre se hace fatalista. “¿Para qué?’”.

Una frustración que también es percibida por Edwards Bello: "Chile es una gran nación frustrada, y por eso mismo hay virtudes que parecen defectos, como ser la instrucción pública, la burocracia y las leyes sociales. Se trata de creaciones que nos quedan grandes" (Edwards Bello, Nuevas Crónicas, “¿Pudo ser Chile una potencia americana?” 63).

Predomina un carácter marcado en el inmovilismo, consecuencia directa del peso de la noche, la metáfora acunada por Diego Portales en su epistolario. Lo que realmente importaba para Portales "era lo que él denominó 'el peso de la noche', esto es, la sumisión social de las clases populares, al orden señorial y jerárquico que verdaderamente presidía y gobernaba el país" (Jocelyn-Holt 27).

Citemos directamente a Portales: "El orden social se mantiene en Chile por el peso de la noche y porque no tenemos hombres sutiles, hábiles y 
cosquillosos: la tendencia casi general de la masa al reposo es la garantía de la tranquilidad pública" (Portales 287).

Según el historiador Mario Góngora, para Portales el principal resorte de la máquina era la distinción entre lo que él llama en sus cartas "los buenos" y "los malos". ¿Y quiénes son los buenos para Portales? Los hombres de orden. Góngora profundiza en el concepto. La paz que busca hacer reinar -o mantener-Portales es la conveniente "a los grandes propietarios, los hombres amantes del orden y la tranquilidad pública” (Góngora 78).

"El régimen de Portales no era 'impersonal' o abstracto sino que el gobierno tenía que apoyarse en una aristocracia. (...) Lo impersonal es propio de una burguesía o de un proletariado industrial, nunca de una aristocracia. (...) El régimen portaliano presupone que la aristocracia es la clase en que se identifica el rango social, y todos sus intereses anexos, con la cualidad moral de preferir el orden público al caos. Esto sería el 'principal resorte de la máquina"” (Góngora 79-80).

Alberto Edwards Vives, en su interpretación histórica del fenómeno de Portales en La Fronda Aristocrática señala: "cuando Portales habla de la tendencia general de la masa de Chile al reposo, pudo decir 'a la pereza', aún con mayor exactitud; pero aquel genial estadista no se equivocaba, ni mucho menos, cuando pensaba que esa tendencia, 'el peso de la noche', el respeto por el hecho consumado, constituía la base más sólida del orden social en este país" (Edwards Vives 136).

Pero para Jocelyn-Holt, subyacente al orden aparente siempre ha coexistido en Chile toda una historia de desorden que amenaza, tal como la naturaleza del país, con desbordar los cauces establecidos. "Ya en 1850 se dice que no son los rotos el temor, sino el "que salgan de sus guaridas"" (Jocelyn-Holt 175). Es la cara oculta del orden, una manifestación de las contradicciones del carácter nacional que se conecta con las incongruencias que desata el culto a lo feo.

Con lucidez, E. Bello señala: "Ni aún ahora, después de dos trastornos en pro de la democracia, el de 1920 y el de 1924, hay gobierno posible sin el apoyo de las derechas conservadoras" (Edwards Bello, Hotel Oddó, “Asesinato de Portales" 55). O también se pregunta: “¿Qué ocurrirá en 1964? Yo les respondería: ¡Nada! ¡Aquí no ocurrirá nada!” (Edwards Bello, Crónicas, "Pobres y Ricos"). Son las garras permanentes e invencibles del espíritu de la Fronda Aristocrática, el aire del poder vital que siempre estuvo en manos de unos pocos, fuerzas conservadoras irresistibles que atraen, absorben, transmutan las revoluciones: en Chile no existe la sierra 
"anfractuosa" donde el rebelde se hace fuerte. La conformación geográfica de Chile, todo lo extravagante que se quiera, es de orden, dominada por una marina de origen inglés, según Edwards. Aparentemente, una vez más.

Así, este peso ancestral de la noche chilena -una suerte de metáfora de su inconsciente colectivo- imprime en su gente características de inercia, pasividad, falta de ideas o de carácter. "Me acostumbré a pensar como roto" dice la estatua del roto que habla en boca de Edwards Bello (Edwards Bello, Crónicas, "Habló el roto chileno" 266). El cariño y la admiración que dice tener el chileno respecto del roto es una mentira para Edwards. Una farsa más. Ser roto es un insulto.

Para ahondar en esta idea, Joaquín Edwards cita al influyente filósofo de la época, el conde de Keyserling:

“ 'El tono dominante del fatalismo chileno, hijo de una región expuesta a terremotos, es una exasperación contenida', dijo Keyserling. En toda nuestra América el filósofo alemán encontró indiferentismo saturado de ironía. En Bolivia, del que ha muerto dicen que quedó indiferente; el gaucho se persigna por las dudas. En nuestras clases populares, cuando muere un conocido dicen: dejó de sufrir. El indiferentismo, expresado de esta manera, parece una negación de toda existencia o trabajo más allá de esta vida" (Edwards Bello, Hotel Oddó, "Milagros y apariciones" 178).

Para Joaquín Edwards, "el asunto está en que hemos visto sin reparos la destrucción de la base emocional de nuestra patria: de la gente morena identificada con el paisaje y desmoralizada bajo la ola inmisericorde de sus explotadores dotados de medios irresistibles para arrollar y vencer" (Edwards Bello, La deschilenización de Chile 19).

Por eso, "el amor de los vascos a esta patria es muy sospechoso, por cuanto ellos han aprovechado la sumisión de nuestro pueblo por el tipo rubio de ojos claros, llegando a hacerlos creer que el tipo moreno es ordinario e inferior. El patriotismo, en muchos casos, es voracidad. El carácter seco, práctico y comercial, de los vascos, destruyó muchas vetas artísticas y algunas ilusiones; en el orden material destruyó el Puente Cal y Canto" (Edwards Bello, La deschilenización de Chile 17).

¿Cuál es la realidad social chilena, que se transformó en 'cuestión’ para las élites pensantes? Ya en la descripción del cónsul inglés Horace Rumbold, en 1876, se manifiesta la brutalidad de los opuestos: "es también un país de violentos contrastes, pues al costado de las construcciones principescas se 
ven los zaquizamíes de la más lúgubre apariencia, la miseria agitando sus andrajos a cada paso, a pleno sol, en lugar de estar relegada a los suburbios alejados del centro" (Romero, Luis Alberto 34).

A fines del siglo XIX Santiago era considerada una de las ciudades más mortíferas del mundo. Desde antes ya, se había instalado la mirada horrorizada que producía la pobreza con sus olores pestilentes y sus miasmas: el hacinamiento, la promiscuidad, el abandono, la tuberculosis, la viruela y la desmoralización eran una realidad que contrastaba con el lujo europeizante de las clases acomodadas. En 1872, Vicuña Mackenna publicó La transformación de Santiago con un descarnado análisis de la cuestión urbana: "Barrios existen que en ciertos días, especialmente los domingos y los lunes, son verdaderos aduares de beduinos, en que se ven millares de hombres, mujeres y aun niños reducidos al último grado de embrutecimiento y de ferocidad, desnudos, ensangrentados, convertidos en verdaderas bestias" (Romero, Luis Alberto 219). Se trataba del Cairo infecto, el potrero de la muerte, en palabras del mismo Vicuña Mackenna. Era necesario construir el cordón sanitario, alejar lo más posible lo intolerable para la vista.

\section{EL HOMBRE DE CHILE Y SUS CARACTERÍSTICAS HISTÓRICAS: BRUTALIDAD, VIOLENCIA, MONSTRUOSIDAD Y HUMOR}

El hombre chileno es una mezcla de durezas y asperezas por lado y lado. Fruto de un "abrazo epopéyico" es el roto. Por el lado de los indios que poblaban la larga franja, su mayoría es de la etnia mapuche, único pueblo originario que sostuvo una agresiva resistencia a los invasores. Por el lado de los ciento cincuenta conquistadores, principalmente de origen andaluz, la brutalidad tampoco escaseaba. Sabían que Chile, palabra maldita, era pobre y con una cruel naturaleza. "Eran soldados sufridos, severos y valientes que habían guerreado en Perú, Colombia y Centroamérica. (...) La dureza y crueldad de los conquistadores y colonizadores, su instinto de rapiña, su aprovechamiento desconsiderado de la mano de obra, su creación de una plebe semi-esclava, ha tenido un largo castigo en su propia sangre, en sus hijos bastardos: los rotos" (Edwards Bello, Crónicas, "No existe homogeneidad de la raza" 114-115).

En sus crónicas, Edwards Bello efectúa un profundo análisis de Chile y su pueblo, de sus orígenes, sus virtudes y defectos: 


\begin{abstract}
"nuestro pueblo es andino-sísmico, a este lado y al otro de los Andes. Keyserling vio claramente el parecido entre Chile y el Japón. Pero nuestra cultura ha despreciado el fondo popular, y las capas superficiales de europeos destruyen en cada oleada a las capas nacionales, sin permitirles el progreso en su propio jugo. De ahí que la masa andino-sísmica viva en perpetua derrota y complejo de inferioridad, reverenciando al europeo rubio en vez de imitar sus métodos y vencerlo, como hacen los japoneses. Más vale el roto que todo" (Edwards Bello, Nuevas Crónicas, “¿Pudo ser Chile una potencia americana?" 62).
\end{abstract}

Es un pueblo que creció desarrapado, duro, sufrido, intemperante, agresivo; que participaba de los defectos y cualidades de esos soldados y de los indios, con una gran fuerza de resistencia y absorción.

Tal es el hombre y tal su naturaleza. Para Edwards Bello, si el signo de la vida mexicana es la calavera escrita, en la vida popular chilena, "es el invunche, esto es la deformación hacia lo monstruoso o repulsivo" (Teillier 31). Y el origen o el símbolo del culto a lo feo está en el invunchismo, una concepción llena de ironía, cuyo origen radica en un mito o leyenda mapuche: "la creación máxima de nuestro indio consistió en el invunche, monstruo humano prefabricado mediante violencias sádicas. La fuerza monstruosa de la idea del invunche se plasmó en la cara de sus autores" (Edwards Bello, Hotel Oddó, "Del obispo Villaroel al mariscal Montgomery" 66).

Los invunches pueden invadir todo el espectro nacional. Pueden ser invunches políticos, invunches literarios, invunches cronistas, todos personajes que simbolizan el potencial de crueldad y violencia del chileno. Son monstruos aparentemente indefensos, repletos de miedo, debilidad y desamparos pero que poseen en su hermético interior algo oculto y que no pueden manifestar, puede ser algo terriblemente poderoso, como la lava que descansa bajo el volcán aparentemente apagado. El invunche es un ser "desesperadamente excluido de sus propias fantasías" (Valdés 141). O sea, un ser frustrado.

"El invunche sobrevive en forma de deformaciones morales, en tergiversaciones de hechos referentes a personas y en el acto de degenerar o de viciar las leyes y las costumbres europeas al poco tiempo de haberlas adaptado a nuestro modo de vivir. Invunche es el niño robado por brujos de raza india y deformado bárbaramente. Le tapan los orificios, le tuercen la cabeza y le ponen los pies en la espalda. Solo el hecho que haya ocurrido esta atrocidad es un motivo para facilitar el camino de ciertos descubrimientos. Si alguien 
descubrió el culto nacional de la fealdad antes de 1922, entonces le concedo la prioridad. El chileno es un ser que se pone en ridículo y pone en ridículo a sus compatriotas" (Edwards Bello, Hotel Oddó, "Crueldad en la literatura latinoamericana, 1954" 83).

Es un ser de cabeza torcida, con los ojos cosidos, boca cosida, sexo cosido, oídos cosidos, todo cosido y envuelto. En esta lucha, el bien y el mal son los centros de la contienda, acompañados de belleza y fealdad, de verdad y mentira.

\begin{abstract}
"Me digo no pocas veces: la industria gangrenosa y cadavérica de los antepasados brujos ha sido lo suficientemente enérgica para perdurar, modificada en el medio moderno. El espíritu de destrucción, la jactancia por la fealdad personal y el aparente desprecio ante ciertas formas de belleza humana, emparentados están con la brujería y fealdad nativas. Hay brujos fabricantes de invunches disfrazados de personas modernas. Juegan al cacho y hasta escriben en los diarios. Viajan y llevan portadocumentos. ¡Cuidado!” advierte Edwards B. (Edwards Bello, El Subterráneo de los Jesuitas, 34).
\end{abstract}

En los años 30, sin que exista aparentemente una relación textual con Edwards Bello, el filósofo alemán Keyserling recoge en sus Meditaciones Suramericanas el tema del culto a lo feo en Chile.

Para Keyserling ya el grito ¡Viva Chile mierda!

"es harto singular y hiere la sensibilidad de los demás suramericanos. (...) Entre los rotos, mestizos de araucano, reina un verdadero culto a lo feo. Los rotos no quieren ser caballeros. Con todo, Chile pertenece a la zona psíquica suramericana, como lo demuestra la existencia allí de una cultura de la fealdad semejante a la de los antiguos Países Bajos. Pocos recuerdos conservo tan plásticos como el del espectáculo de la fiesta nacional chilena, precisamente porque la vi destacada sobre el fondo del culto de la belleza imperante en el resto del continente suramericano. (...) Y la cueca, frenéticamente bailada entretanto, es el más feo de los bailes nacionales. Cuanto más grotescamente es bailada, cuanto más feos son los bailarines y, sobre todo, más viejas y avellanadas y deformes las mujeres, mejor y más castizo estilo se le encuentra. El final de la fiesta es de un tal salvajismo, que la fuerza armada tiene que intervenir para despejar un verdadero campo de batalla" (Keyserling 226-227). 
La crueldad es para Edwards Bello otra expresión de lo feo. A propósito del entusiasmo que despiertan los fusilamientos, los crímenes y las muertes en Chile, Edwards Bello sostiene:

\begin{abstract}
“aquí la muerte es un espectáculo, y usted habrá notado que hace salir de su anonimato a docenas de personas, mayores o de edad mediana, que se han hecho especialistas en "cadaverear". (...) No es raro que aquí lo impersonal tenga más valor que lo vivo y presente. Es una forma de atacar las iniciativas, de hacer menores los éxitos personales y, en fin, de cultivar el fracaso. El medio es mediocre, y mucha gente ve en la muerte una compensación para su propia agonía permanente" (Cit. en García-Huidobro 322).
\end{abstract}

Es el tan chileno apocamiento del otro, la soterrada envidia nacional, la alegría por el fracaso ajeno, la hipocresía de la maledicencia habitual, la incapacidad por decir las cosas de frente, tal cual son. "Es costumbre nacional no ver el progreso propio por uno mismo sino por hundimiento de otro compatriota. El que sube no hace subir a otros, sino que se vale de los otros, a manera de trampolín, encaramándose en sus espaldas" (Cit. en García-Huidobro 341), observa agudamente Edwards. Porque hay dos malarias, la malaria patológica y la malaria psicológica, descubierta en Chile.

Hasta la mendicidad adquiere en Chile un carácter de soterrada agresividad. Como si los que algo poseen tuvieran que pagar por ello. Este peaje de la pobreza es una realidad común para cualquier dueño de auto en Santiago. Si no le da lo que el cuidador pide, el peligro es el rayón en la carrocería o los neumáticos reventados en el mejor de los casos; el robo en el peor. Nada nuevo:

"El importuno y el latero forman legión y en muchos aspectos se parecen a los mendigos. No hay tierra donde pidan más que en Chile; desde que uno sale a la calle ya tiene a los talones el mendigo; en sus múltiples manifestaciones, este mendigo no nos soltará hasta la noche. La mendicidad nacional revela muchas cosas: fracaso, pobreza, cinismo, sinvergüencería, cobardía del público y ausencia de la autoridad. La gente tiene miedo de decir que no, de gritar, de indignarse. En pocas partes piden con la audacia, a veces siniestra, de esta capital" (Edwards Bello, Francisco Miranda y otros personajes, "Importunos y lateros en la vida nacional" 188). 
No obstante, para Keyserling el chileno es el pueblo de más carácter y el menos embustero en Sudamérica, de ahí concluye que la verdad se asocia a la brutalidad, logrando "una aprehensión definitivamente justa de las raíces telúricas de las distintas culturas posibles. Si las que tienen por base la Verdad nacen de una brutalidad primaria, las determinadas por la Belleza tienen en la Mentira sus raíces" (Keyserling 229).

Pero en su descarnado análisis, Edwards Bello no deja nunca de revelar el oscuro humor nacional. La mezcla de burla y de tragedia es una característica muy chilena "¿Cómo te ha ido con los temblores?" (Edwards Bello, Crónicas, "La tragedia chilena" 72). Nos reímos de nosotros mismos. No nos concedemos importancia. Nos burlamos de todo. La risa es un condicionamiento ante la percepción de que somos unos sobrevivientes.

Edwards Bello asume como propio ese humor negro. Juega con la alternancia en su escritura entre el distanciamiento, la mirada fría y analítica, el contraste y la posterior empatía con las características descritas. Ello se manifiesta en la elección de los temas que hace este escritor, muchos de ellos históricos, en los que los sueños de gloria contrastan con lo absurdo de la mediocre realidad, cotidianidad y el carácter insular del chileno.

Una incapacidad para tomarse las cosas en serio que también refleja Luis Oyarzún en su diario:

"El hispanoamericano suele ser el más intolerable de los críticos, con lo que resulta imposible complacerlo, y como no parece tomar en serio nada que no sea la vida misma con todas sus contradicciones, crueldades e intemperancias, no es fácil gobernarlo. Acaso Portales en Chile contribuyó a su propio éxito con esa combinación de humorismo, sensualidad y dureza que caracterizaba a su personalidad y merced a la cual pudo imponerse sobre sus contemporáneos, sin tomarse a sí propio demasiado en serio" (Oyarzún 62).

El humor está presente en la descripción del roto disfrazado de ropa vieja desechada por elegantes del centro:

"Son graciosos, con gracia del sur de España. Más graciosos y ocurrentes que los aristócratas con sangre de vascos. Si no fuera por sus ojos algo oblicuos y el pelo tan recio, parecerían caballeros castellanos, con sus bigotazos y ojos moriscos. Ese pelo que les reduce las frentes, bajando en las regiones temporales, es la hipoteca de las indias de la Conquista. No rehúyen los duelos a muerte ni buscan testigos. Se baten con cuchillos. Suelen morir juntos bajo las estrellas 
en charcos de sangre" (Edwards Bello, Hotel Oddó, "Chuchunco, ayer y hoy" 44-45).

\section{EL CONSTANTE DESVANECIMIENTO DE UN DECORADO: EL CULTO A LO FEO EN LO URBANO Y LA DEMOLICIÓN DE LA CIUDAD}

Este desgarro del chileno se manifiesta en una brutalidad y torpeza en los actos públicos. Lo que Luis Oyarzún llama la "elementalidad de la vida exterior". "Mi país me produce la impresión de estar habitado por ánimas de devorador e infuso subjetivismo, en un plano inferior a la espiritualidad". Estas ánimas incapaces de contemplar la belleza natural arrasan en cambio con ella y construyen en las ciudades espantosos edificios. A la par se destruyen los pocos lugares con cierto valor arquitectónico, o simplemente las graciosas casas coloniales y sus jardines.

Santiago es un lugar de cortes y quiebres, en el que reina la desarmonía y donde solo sobreviven pequeñas islas de belleza, o armonía más bien, en peligro de extinción. Santiago es una ciudad donde para Edwards Bello no existe un plan conjunto, el habitante tiene permiso de construir según su capricho personal, es una capital que progresa por horas pero sin método. Es literalmente una ciudad que ha estallado en una serie de protuberancias ambiguas (Lefebvre 10). Dice Edwards:

"En nuestra tierra no podría darse el caso de un genio parecido al de Haussmann, no por ausencia de talentos ni de especialistas, sino por ausencia de unidad y de consorcio de las voluntades. Además de eso, nuestros arquitectos mejores obedecen a contratos comerciales de vasta envergadura financiera y de escasas miras al futuro colectivo. (...) No se ve la cabeza por ninguna parte. (...) La ciudad actual-se lo dirá cualquier urbanista extranjero- es fea por sus edificios disímiles y por sus calles con entrantes y salientes; en cambio, es hermosa su situación en el valle andino" (Cit. en García-Huidobro 228).

Pero lo más grave es que Santiago es una ciudad que carece de alma: "En América, las ciudades carecen de eso: no tienen alma. Como diría Unamuno; no están impregnadas de humanidad" (Edwards Bello, Crónicas Reunidas (I) 1921-1925, "Santiago y Luis Barros Borgoño" 465-468). Esta idea coincide con la expresada por Luis Oyarzún en su "Resumen de Chile": "Una tierra con muchas sangres derramadas y sin mitos realmente propios, es decir, en este sentido antropológico, sin alma" (Oyarzún, Temas de la cultura chilena 
12). O, como escribiera Fray Camilo Henríquez, "Chile es un país donde falta todo" (Cit. en Oyarzún, Temas de la cultura chilena).

Ciudad sin alma, hombres sin imaginación:

"No hay enseña ni leitmotiv original. Ni los afiches. Conozco dos o tres personas con ideas propias. Las demás tienen la opinión del último libro que leyeron y de la última persona que escucharon. La vida social carece de ficción. Todo es parodia. Repetición de modas y maneras. ¿Y la música? Mi duda es mortal. Me parece que obro chilenamente al sentirme frustrado en un país frustrado. Solamente los muy ignorantes pueden ser felices" (Edwards Bello, Francisco Miranda y otros personajes, "Frustración" 176).

Es el defecto de la falta de imaginación, el 'optimismo de patos' de Pablo de Rokha. "Cada día que pasa me siento más raté, o fracasado. No soy el único que experimenta complacencia en la angustia del fracaso" (Edwards Bello, Francisco Miranda y otros personajes, "Frustración" 174).

El fenómeno de la monotonía se explica, según Edwards, por la excesiva extensión del terreno construido y escasez de habitantes. Santiago es una capital monótona, trazada a cordel y que no tiene ni una sola callecita estrecha, tortuosa, antigua, no tiene lo imprevisto: "Allá (España) las ciudades, los pueblos, cerrados por antiguas murallas, concentraban la vida, la hacían más jugosa, más intensa; aquí, los pueblos y las ciudades sin límites se estiraban, perdían su esencia, su vigor, en el afán de espaciarse. Por eso América es todavía una nebulosa: no tiene la fuerza astral que da la concentración fraternal" (Edwards Bello, Crónicas Reunidas (I) 1921-1925, "Nuestros pueblos y el carácter nacional" 20).

Es un pauperismo de la conciencia sensible para Luis Oyarzún. "Nada hay, sino polvo, hollín, huesos y trapos tirados por el suelo, piedras grisáceas, hierbajos secos bajo el sol del verano. Esta es la ciudad del polvo". Un polvo gris, como de una cantera enorme, y ello en unos tiempos previos a los actuales niveles de contaminación ambiental. Mirar a Santiago es mirar a través de un vidrio sucio. La suciedad lo invade todo, las micros nuevas terminan en pocos meses pareciéndose a las desastrosas antecesoras, los hoyos destruyen los vehículos, sueltan los tornillos y transforman en cacharro a todo, hasta a los seres humanos que allí se desplazan. Es plausible imaginar que Edwards Bello habría escrito una -o varias- ácidas crónicas sobre el Transantiago y la perenne agresividad del micrero chileno. "La vida de un autor se mide por la vida de su obra. Un autor vivo puede estar ya muerto si al abrir sus libros 
no encontramos con quien dialogar", escribió Jorge Teillier (30). La voz de Joaquín Edwards Bello sigue siendo nueva. Aún podemos dialogar con él.

Sin alma, sin conciencia, sin capacidad de contemplación, la ciudad es un reflejo de lo que son sus hombres, de su ceguera y falta de perspectiva, de su profunda escisión y desgarro con respecto de su propio pueblo. Como ya lo esbozamos, en la ciudad se da la cara más abyecta de la pobreza:
"Santiago, con sus barrios bajos infectos, sus postes de teléfonos y el basural que lo circunda por falta de hornos crematorios, es como un pie sucio y fétido con zapato Luis XV. No hay proporción entre los palacetes del Parque Forestal, la calle Dieciocho y Alameda, y los ranchos y conventillos que se suman por miles y miles. Por un palacete de repostería hay diez mil ranchos de barro: por un niñito blanco y robusto hay diez mil fetos vivientes color aceituna. Chile aborda, casi sin saberlo, un problema social muy grave, porque se trata de una nación semieuropea que no alcanza a digerir al indio, o viceversa" (Edwards Bello, Crónicas Reunidas (I) 1921-1925, "El asesinato de la calle Santa Rosa” 228).

En las zonas periféricas de las grandes ciudades se formaron los rancheríos o poblaciones callampa, invisibles para el turista, donde se hacinan y sobreviven quienes no pertenecen a la sociedad normalizada. En Valparaíso, por ejemplo, ciudad predilecta de Edwards, se produce un fenómeno similar al descrito por el historiador argentino José Luis Romero respecto de la aparición de rancheríos en Acapulco "desde cuyos cerros parecían vigilar el desborde de la riqueza, mientras sus habitantes se introducían entre las rendijas de la sociedad ociosa tratando de obtener algún provecho" (Romero, José Luis 357). Una cara oculta del progreso, la ciudad anómica que forma una especie de anfiteatro que rodea la ciudad normalizada y que la vigila. El drama y la perpetuación de la pobreza tenían una faceta en tiempos de Edwards Bello que no difiere en tan gran medida con la actual. El barro de los ranchos se cambió por los tabiques precarios y los ladrillos porosos. La tierra y el polvo siguen levantándose en las poblaciones. Pese a los artefactos electrónicos adquiridos mediante el endeudamiento de los créditos de las multitiendas (el sobregiro, otro tema de larga data abordado ampliamente en las crónicas de Edwards Bello y que daría para un estudio en sí), la realidad social urbana actual no difiere mucho de la retratada por el escritor chileno:

"La calle Borja es una hilera de ranchos de barro con techos torcidos, sin pavimento ni aceras. Las casas parecen hinchazones de la tierra. 
Los habitantes tienen el color terroso de sus viviendas. Sus miradas y sus silbidos parecen provenir de honduras terrestres. Los menores suelen mostrar ojos oblicuos, pómulos salientes y cabellos tiesos que bajan a la frente hasta cubrir la región temporal. Cada rincón de dicha calle podría contar siniestras aventuras. En las viviendas no hay mueble sano. Las sillas y las mesas están cojas. Los espejos trizados, opacos. Las camas con colchones despancijados justifican la estadística en su crueldad: una cama para cien habitantes. Los vasos trizados, las tazas sin azas, los vidrios rotos. Angosta acequia negra canta su lúgubre canción. Personas, caballos y perros han disminuido en tamaño. Los ratones crecieron y los gatos disminuyeron. Los ratones o pericotes, calvos, con ojos maliciosos, de tinterillos, hacen huir a los gatos y suelen morder a las criaturas. Las murallas desconchadas y chuecas son pegaletreros de propagandas politiqueras. Cada rincón es letrina. En los días de sol las madres despiojan a sus críos con naturalidad y arte de peinadoras" (Edwards Bello, Hotel Oddó, "Despedida de la Sombrerería Presciutti" 26).

Esta descripción de lo crudo de la pobreza muestra la capacidad de distanciamiento y cercanía simultáneos que posee la escritura naturalista de Joaquín Edwards ante lo feo y lo monstruoso de su gente. Existe una capacidad de tomar distancia y efectuar una autocrítica muy fuerte, pero al mismo tiempo se percibe una reivindicación de las peculiaridades de lo chileno como propias. Edwards Bello adopta estas características y el tipo de humor profundamente chileno como si fuera un pariente pobre allegado:

"Parte del paisaje son los postes ladeados con redes de alambres. En invierno caen como borrachos. Hoteluchos por horas alquilan camastros con olores variados a orinas, a amores, a sudores de muchos cuerpos, con chinches y pulgas veteranas. Busconas, o corteras, acechan con ojos de una audacia mezclada con dulzura inconcebible. Las hay tuertas, con costurones de boca a oreja, disimulados con cremas y polvos. Las casas son de materiales ligeros. Los derrumbes frecuentes. Errores de cálculo o cemento adulterado. Frente a la estación se derrumbó una casa a medio construir. En la red de andamios perecieron dos obreros. No pudo establecerse la causa" (Edwards Bello, Hotel Oddó, "Chuchunco, ayer y hoy" 44).

La capital chilena padece de una fealdad cósmica. "Difícilmente habrá ciudad más fea, miserable, sucia y deprimente en el mundo entero", escribe con tristeza Luis Oyarzún (Diario íntimo 187), quien se desplazaba por 
todo el globo. "Más que aldea grande, Santiago es una gran aglomeración de aldeas parchadas, remendadas, unidas por las redes de tranvías", agrega nuestro cronista (Edwards Bello, Crónicas Reunidas (I) 1921-1925, "Nuestros pueblos y el carácter nacional" 17). En otra parte dice: "Santiago sería una ciudad interesante si la hubieran construido con cabeza. No hay poesía ni leyenda" (17). Al referirse al culto de lo feo en la ciudad, Edwards alude nuevamente a las "fuerzas secretas enemigas de la hermosura" (17), son las fuerzas imbunchistas que atacan a la Alameda, al puente Cal y Canto, "estas fuerzas anónimas hieren sin aviso previo, como terremotos (...). La fuerza productora de monstruos es perspicaz y astuta. No tarda en descubrir lo bello para convertirlo en horrible. Así pasó con la Pérgola de las Flores de la Plaza de San Francisco. Esa joya fue mutilada y conducida al lugar más feo de Santiago".

Porque un aspecto central del culto a lo feo en la ciudad es la tendencia, al parecer irrefrenable, que tienen los chilenos por demoler lo poco rescatable. Curiosamente las aberraciones arquitectónicas suelen sobrevivir a los embates de la demolición. Todo ciudadano de los años 2000, como aquel de los 1900 ha experimentado la extraña sensación de vivir en un decorado sometido a un constante desvanecimiento. Esta crítica de la vida cotidiana constituye uno de los tópicos centrales de las crónicas que publicaba Joaquín Edwards Bello en el diario La Nación. "El chileno construye bien, pero demuele mejor, y cuando echa abajo algo lo hace con alegría. Es la manía destructiva que nos preside y nos gobierna. Hasta en la 'presidentofagia' se ve esto. De Valdivia a Frei, siempre igual" (Cit. en García-Huidobro 228).

Por eso, si bien en la mayor parte del mundo las ciudades siguen pareciéndose a sí mismas aunque pasen los decenios, en Chile, las ciudades se transforman de una década a otra, los barrios se metamorfosean y un nativo citadino puede simplemente no reconocer absolutamente nada de ciertos barrios de la capital. Esto es real hoy y ahora en el centro, Nuñoa, Las Condes, etc., y era igualmente real cuando Edwards volvió en los años 20 a Valparaíso luego de su larga estadía en Europa y se encuentra con ruinas y tristeza:

"Todo lo vi cambiado, terremoteado, las casas deshechas, el colegio
reformado, la calle patas arriba, los amigos emigrados o meta-
morfoseados. iQué tristeza tan grande ser porteño! Esta tierra sin
tradiciones, sin recuerdos. En Europa un burgués vive veinte años
en el mismo barrio; si sale y vuelve lo encuentra todo casi igual: la
tienda, la casa, el colegio, el teatro, la iglesia. En Valparaíso todo se 
fue, todo se transformó de una manera radical, diabólica" (Edwards Bello, Crónicas, "Tierra de temblores" 91).

Es otro el mundo que toma el lugar de aquel que era conocido, "el decorado se ha ido de a poco desvaneciendo" (Edwards Bello, Hotel Oddó 13). En Chile, el pasado es un fantasma despreciable. "Progresar se me aparece con cierto aspecto de tristeza. Esta ciudad de Santiago ha crecido de tan monstruosa manera que podríamos decir: Chile es un país a una ciudad pegado, parodiando a Quevedo, cuando dijo de un narigón que era un hombre a una nariz pegado" (Edwards Bello, Francisco Miranda y otros personajes 62).

¿Por qué demuelen en Chile? Por imprevisión, por costumbre y por el negocio del momento responde Edwards Bello (Edwards Bello, Nuevas Crónicas 131). El restaurante La Bahía nunca tuvo tanto público como para su demolición, feliz por el cambio, la polvareda y el bochinche, "el público se apretujaba entre los andamios y el cascote, más feliz de comer y beber en medio de una ruina que en un comedor de estilo. De noche cazábamos ratones, mejor dicho, pericotes, con carabinas" (Edwards Bello, Nuevas Crónicas 133).

Los chilenos son cultores de la civilización del water-closet, "el porteño no entiende de antiguallas, de cachivaches mohosos y polvorientos; todo ha de ser nuevo y flamante; le gusta el cambio; se aburre de todo; como un eterno niño quiere siempre una cosa nueva. Mira el incendio con gusto, primero porque es bombero y segundo porque piensa que ahí donde arde una casa vieja ha de alzarse una nueva, recién barnizada, con termosifón y calefacción y agua corriente" (Edwards Bello, Crónicas, "Tierra de temblores" 93).

Con ironía, el cronista capta la capacidad de adaptación a la tragedia que vimos con anterioridad:

"La gente vive apresurada, quiere que todo cambie y mude y se transforme. Es la fuerza, el vigor enorme del puerto: la evolución, la fuga. Cuando habla del terremoto, la gente palidece. Se veían luces en el cielo, dicen. Todo se derrumbó, y algunos cadáveres del cementerio, desmoronado, llegaron a la planta baja. Fermentó la hez: estupro, robo, incendio; fue como un festín de chacales el terremoto. (...) Ninguna sociedad más elástica y más conforme con las alzas y bajas de la vida. El incendio es un buen negocio" (Edwards Bello, Nacionalismo continental 79-83). 
Una tragedia que no podía dejar indiferente a un alma sensible. La razón de ser de Edwards Bello estuvo en su escritura. Mientras pudiera seguir alimentando su enorme archivo y relacionando las distintas temáticas con la realidad circundante, podía seguir viviendo: "su sensibilidad a flor de piel, chocaba de continuo con el ambiente; era su llaga abierta y también su acicate. Quejarse constituía su fuerza", escribió Alone a horas de la muerte de Edwards (Díaz Arrieta 35). Joaquín Edwards Bello era un expatriado en su propia patria.

Y como en Chile el arte ha consistido en sacar belleza de la fealdad, del absurdo, de la pequeñez, del sinsentido, el cronista es capaz de develar con ironía su más profunda postura vital a partir de un simple cartel, símbolo de la pérdida constante que está detrás del culto a lo feo, la demolición y el invunchismo. "En la ventana de Presciutti un letrero dice: 'Nos vamos'. Eso es. Nos vamos. Es mejor irnos de una vez, como en mi sueño. Este mundo que viene trae signos terribles. Hay palabras nuevas que silban por el aire como enormes culebras apocalípticas. Palabras como azotes: megatones, astronautas, estratósfera" (Edwards Bello, Hotel Oddó, "Despedida de la Sombrerería Presciutti” 26).

Y ¿cuál era el sueño de Joaquín Edwards Bello?

Morir disparándoles a unos bandidos "de pie y en pocos segundos, no en cama, entre chatas, potingues y frascos. (...) El destino me ha negado ese minuto de gloria, pero no pierdo las esperanzas. Viajo siempre con mi revólver, sin perder de vista la puerta de mi vagón" (25).

Y la puerta se abrió para dar paso al sueño y a la dignidad.

\section{BIBLIOGRAFÍA}

Díaz Arrieta, Hernán. “Muerte de J. E. B.”. El Mercurio, 20 de febrero de 1968, en Revista Árbol de Letras, 4 Vol. Marzo 1968.

Edwards Bello, Joaquín. Crónicas. Santiago de Chile: Talleres La Nación, 1924.

Nacionalismo continental. Madrid: Imprenta G. Hernández y Galo Saéz, 1925. Crónicas. Santiago de Chile: Zig-Zag, 1964.

Nuevas Crónicas. 1952. Selección de Alfonso Calderón. Santiago de Chile: ZigZag, 1965.

El Subterráneo de los Jesuitas. Selección de Alfonso Calderón. Santiago de Chile: Zig-Zag, Selección Alfonso Calderón, 1966.

Hotel Oddó. Selección de Alfonso Calderón. Santiago de Chile: Zig-Zag, 1966. 
Francisco Miranda y otros personajes. Selección y ordenación de Alfonso Calderón. Santiago de Chile: Editorial Andrés Bello, 1970.

El Marqués de Cuevas. Santiago de Chile: Biblioteca Popular Nascimento, 1974.

La deschilenización de Chile. Selección y ordenación de Alfonso Calderón. Santiago de Chile: Ediciones Aconcagua, 1977.

Crónicas Reunidas (I) 1921-1925. Edición a cargo de Roberto Merino. Santiago de Chile: Ediciones Universidad Diego Portales, 2008.

Edwards Vives, Alberto. La Fronda Aristocrática, Historia política de Chile. Santiago de Chile: Editorial del Pacífico, 1959.

García-Huidobro, Cecilia. Un transatlántico varado en el Mapocho. Santiago de Chile: El Mercurio Aguilar, 2005.

Góngora, Mario. Ensayo histórico sobre la noción de Estado en Chile en los siglos XIX y XX. Santiago de Chile: Editorial Universitaria, 1986.

Jocelyn-Holt, Alfredo. El peso de la noche, nuestra frágil fortaleza histórica. Santiago de Chile: Editorial Planeta, 1997.

Lefebvre, Henri. La revolución urbana. Madrid: Alianza Editorial, 1970.

Oyarzún, Luis. Temas de la cultura chilena. Santiago de Chile: Editorial Universitaria, 1967.

Diario íntimo. Edición y prólogo Leonidas Morales. Santiago de Chile: Departamento de Estudios Humanísticos, Universidad de Chile, 1995.

Portales, Diego. Epistolario. Tomo 1. Santiago de Chile: Ediciones Universidad Diego Portales, 2008.

Romero, José Luis. Latinoamérica: las ciudades y las ideas. Buenos Aires: Siglo XXI, 2001.

Romero, Luis Alberto. ¿Qué hacer con los pobres? Santiago de Chile: Ariadna Ediciones, 2007.

Serrano, Miguel. "El chileno vive angustiado por su paisaje". Revista Historium. XI/124 (1949), en Desde la Atlántida, Conversaciones con Miguel Serrano, Rafael Videla Eissmann. Santiago de Chile: Editorial Puerto de Palos, 2007.

Teillier, Jorge. "Conversación póstuma con Joaquín Edwards Bello". Revista Árbol de Letras, 4. Vol. Marzo 1968.

Uribe, Armando. "Caballeros" de Chile (edición en francés de 1978). Santiago de Chile: Lom Ediciones, 2003

Valdés, Adriana. "El "imbunche", estudio de un motivo literario en El Obsceno Pájaro de la Noche". Donoso, la destrucción de un mundo. Buenos Aires: Ed. Fernando García Cambeiro, 1975.

von Keyserling, Hermann. Meditaciones suramericanas. Madrid: Espasa-Calpe S.A., 1933. 